\title{
UNIVERSIDADE E DEMOCRACIA: REFLEXÕES SOBRE OS PROCESSOS DE INDICAÇÃO DE REITORES NO ENSINO SUPERIOR PÚBLICO BRASILEIRO
}

\author{
Renata Cecilia Estormovski ${ }^{1}$ \\ https://orcid.org/0000-0001-5714-8928
}

RESUMO: A nomeação de reitores em parte das universidades federais brasileiras, no ano de 2019, não seguiu a indicação das comunidades acadêmicas, com a formalização, pelo governo federal, de sujeitos distintos daqueles apontados pelos processos de escolha particulares. Este artigo visa construir uma reflexão sobre as implicações desse movimento para a democracia e, para isso, parte do materialismo históricodialético como referencial teórico-metodológico e realiza uma análise documental. Com tal construção, compreende-se que a questão analisada está em relação com a conjuntura macroestrutural atual, em que preceitos neoliberais - intensificados pelo neoconservadorismo - buscam o esvaziamento democrático das instituições públicas como forma de articulá-las aos preceitos capitalistas e a valores morais.

PALAVRAS-CHAVE: Ensino Superior, gestão universitária, democracia, neoliberalismo.

\section{UNIVERSITY AND DEMOCRACY: REFLECTIONS ON THE PROCEEDINGS OF DEANS IN PUBLIC HIGHER EDUCATION}

ABSTRACT: The appointment of deans in part of Brazilian federal universities, in 2019, did not follow the recommendation of academic communities, with the formalization, by the federal government, of subjects different from those appointed by the particular choice processes. This article aims to build a reflection on the implications of this movement for democracy and, for that, part of the historical-dialectical materialism as a theoretical-methodological framework and performs a documentary analysis. With this construction, it is understood that the question analyzed is related to the current macro-structural situation, in which neoliberal precepts - intensified by neoconservatism - seek the democratic emptying of public institutions as a way of articulating them with capitalist precepts and moral values.

KEYWORDS: Higher Education, university management, democracy, neoliberalism.

1 Mestranda em Educação, Universidade de Passo Fundo. Bolsista Capes, Passo Fundo, RS, Brasil renataestormovski@gmail.com 


\section{UNIVERSIDAD Y DEMOCRACIA: REFLEXIONES SOBRE EL PROCEDIMIENTO DE LOS RECTORES EN LA EDUCACIÓN PÚBLICA SUPERIOR}

RESUMEN: El nombramiento de rectores en parte de las universidades federales brasileñas, en 2019, no siguió la recomendación de las comunidades académicas, con la formalización, por parte del gobierno federal, de materias diferentes a las designadas por los procesos de elección particulares. Este artículo tiene como objetivo construir una reflexión sobre las implicaciones de este movimiento para la democracia y, para eso, parte del materialismo histórico-dialéctico como marco teórico-metodológico y realiza un análisis documental. Con esta construcción, se entiende que la cuestión analizada se relaciona con la situación macroestructural actual, en la que los preceptos neoliberales, intensificados por el neoconservadurismo, buscan el vaciamiento democrático de las instituciones públicas como una forma de articularlas con los preceptos capitalistas y los valores morales.

PALABRAS CLAVE: Educación superior, gestión universitária, democracia, neoliberlismo.

\section{Considerações iniciais}

No contexto político e econômico atual, em que concepções neoliberais e neoconservadoras intensificam desigualdades e acirram conflitos sociais, a democracia tende a se enfraquecer nas instituições, sendo considerada prejudicial ao desenvolvimento e à eficiência da esfera estatal. Essa percepção afeta as universidades públicas, sendo que recentemente seis delas foram expostas a estratégias arbitrárias de instâncias superiores com vistas a esvaziar a participação em seus processos de gestão. Em 2019, houve a nomeação, em diferentes instituições de ensino superior, de reitores que tiveram menor representatividade em consultas públicas realizadas nas comunidades acadêmicas ou entre colegiados, ou que não chegaram a fazer parte desses processos, mas que possuíam vínculo com interesses da equipe atuante no governo federal. Por mais que até aquele momento não houvesse garantia jurídica para a oficialização do nome que figurava como preferência da comunidade pelo governo federal, essa atitude já era tradicional em governos anteriores, causando desagrados na academia que se intensificaram com a publicação de uma medida provisória, nos últimos dias do ano, garantindo poder de decisão ao Presidente da República.

Diante desse cenário, este estudo objetiva construir uma reflexão sobre as implicações desse movimento para a democracia nas universidades 
públicas, não somente em seus processos de gestão, mas no cotidiano acadêmico. Faz-se isso a partir da análise de documentos que expressam tanto o ordenamento jurídico que regulamenta a escolha de reitores em instituições de ensino superior públicas quanto a forma particular com que houve a intervenção nas tomadas de decisão em seis delas. Construído a partir do materialismo histórico-dialético e utilizando o conceito de relação elaborado por Lukács (1978) como forma de associar a realidade empírica à teoria e, com isso, chegar à compreensão da realidade concreta a que se propõe, o estudo se organiza em três seções e busca responder a pergunta que move a pesquisa: Quais são as implicações da interferência do governo federal na nomeação de reitores não-indicados em instituições públicas de ensino superior para a construção da democracia nas universidades?

\section{Concepções de democracia e universidade em relação}

Propostas, decisões e até mesmo opiniões, quando veiculadas por autoridades no âmbito público, constituem elementos que se tornam potenciais para as políticas e para a gestão pensadas no âmbito estatal. Os sentidos trazidos por discursos ou ações referem-se a formas de se conceber um problema de interesse público e estão vinculados a distintas concepções, que materializam formas de se compreender o contexto político, econômico e social. Nesse sentido, Lukács (1978) afirma que há uma relação dialética constante entre o singular e o universal, que são mediatizados pelo particular. Assim, micro e macro contextos estão associados e em movimento contínuo, com situações específicas que se tornam o elo entre esses âmbitos. Neste estudo, tal vinculação se torna a ferramenta que demonstra a associação entre decisões tomadas quanto à gestão pública universitária e suas percepções de democracia com a atual conjuntura, permitindo a construção das reflexões almejadas.

Tendo-se o materialismo histórico-dialético como condutor dessa construção, entende-se a necessidade de se explicitar que o Estado, principal agente de proposição das políticas públicas, não atua de forma neutra nem pelo bem comum na sociedade capitalista, mas representa um "instrumento de dominação de classe" (HARVEY, 2005, p. 84). Age, assim, de forma que a estrutura pública favoreça aos interesses de grupos dominantes, seja administrando crises, provendo bens públicos ou ofertando estrutura física e social por meio da criação de um "interesse geral ilusório", sistematizado por Harvey (2005, p. 81). A democracia, compreendida nesse contexto, também possui significações diversas de acordo com as concepções de mundo e dos interesses 
dos sujeitos que se utilizam desse conceito. Em sua construção polissêmica, torna-se possível identificar maneiras distintas e até mesmo controversas de se conceber a participação nas tomadas de decisão.

A separação entre a arena política e a esfera econômica, que Wood (2003) argumenta ter sido perpetuada pela apropriação e pela exploração feitas pelo capitalismo e incorporadas como seu principal mecanismo de defesa, se configura, para a autora, como uma forma de impedir a construção da democracia. Por meio dessa divisão estrutural, questões essencialmente políticas, como "a disposição do poder de controlar a produção e a apropriação, ou a alocação do trabalho e dos recursos sociais" (p. 28) são esvaziadas e transformadas em preocupações apenas econômicas. O poder político, assim, é privatizado; a sociedade é tratada como uma abstração; e as relações de produção são consideradas naturais e eternas (WOOD, 2003). As lutas, então, quando ocorrem em uma esfera não atingem a outra, impedindo um movimento que aproxime os dois polos e propicie a integração necessária para que a sociedade se constitua de maneira distinta e supere a dicotomia instituída e delimitadora da participação e da coletividade.

Mészáros (2002) discorre sobre como a separação entre dois polos, o de ação econômica e o de ação político-parlamentar, enfraquece o movimento político dos cidadãos e, consequentemente, impede a constituição da democracia. Considera, nesse sentido, que o controle social, do qual o capital historicamente se apropriou com a alienação da participação do corpo social, precisa ser retomado. A criação de hierarquias de atuação dos indivíduos nas decisões, que se constituiu por meio de um processo de destituição de poder do povo, para o autor, precisa ser invertido através da emancipação política. Essa construção, contudo, deve se dar a partir de um novo sistema metabólico em que se instaure uma sociabilidade divergente da atual, dessa vez autodeterminada pelos sujeitos. Para isso, Mészáros (2002) frisa que não há um modelo de democracia a ser seguido ou uma pré-determinação teórica, mas que "programas e instrumentos de ação sociopolíticos verdadeiramente adequados só podem ser elaborados pela própria prática social crítica e autocrítica no curso de seu efetivo desenvolvimento" (p. 1008).

Em relação com essas perspectivas, Vieira (1998) ratifica a concepção de democracia como um processo, não havendo, assim, um estágio democrático, mas uma construção em que o controle social é regido pelas tomadas de decisão da população. Para ele, "quanto mais coletiva é a decisão, mais democrática ela é" (p. 12). A coletivização dessas decisões, a ser buscada em um grau cada vez mais crescente, implica também, para o autor, que os interesses 
discutidos não envolvam particularizações, mas preocupações relevantes para todo o conjunto de trabalhadores.

No contexto neoliberal, contudo, como reforça Peroni (2015), a democracia é considerada como motivo de ineficiência e ineficácia e a sua permeabilidade no Estado e nas políticas públicas precisaria ser contida. Como a autora destaca, para os neoliberais, o investimento em políticas sociais seria utilizado pelos governantes como forma de se manterem no poder, promovendo um saque à propriedade privada ao distribuir a renda produzida por um grupo e interferir no livre mercado. A supressão total da participação dos sujeitos através do voto, todavia, não seria possível, prescrevendo-se, assim, o esvaziamento da atuação popular nas instituições públicas e em seus processos de tomada de decisão. Com isso, há um aprofundamento das distâncias entre o político e o econômico, preconizado por Wood (2003), e o setor privado acaba ocupando espaços que deveriam ser preenchidos pela ação estatal. Os distintos processos de privatização da esfera pública, nesse contexto, se aprofundam (PERONI, 2015) em relação com a destituição da democracia nesse âmbito, guiada por promessas de aprimorar, qualificar e retirar de uma crise constante as esferas governamentais.

Em um cenário recente, as concepções neoliberais têm sido dinamizadas e aprofundadas com a eclosão de discursos neoconservadores, que passaram a orientar as políticas públicas e a gestão das instituições. Como Harvey (2005) argumenta, o neoconservadorismo é "perfeitamente compatível com o programa neoliberal de governança pela elite, desconfiança da democracia e manutenção das liberdades de mercado" (p. 92). Aliás, o caos e a insegurança causados pelo individualismo (HARVEY, 2005) que se aprofunda nas sociedades capitalistas têm na moralidade, nos valores e na ideia de saudosismo quanto à uma ordem fantasiada como vivida no passado uma resposta. Salienta-se como uma forma de conter certa permissividade moral, citada por Harvey (2005) e identificada no presente nos discursos de dados grupos, que no Brasil vislumbram a universidade pública como um de seus pontos de ataque, como será discutido posteriormente.

Na concepção de Chauí (2003), a universidade, que já surge como uma entidade social pautada na autonomia e em ordenamentos, normas e valores próprios, denota, até a contemporaneidade, o modo pelo qual a sociedade funciona. Independente do Estado e da igreja a partir da Modernidade, após a Revolução Francesa fortaleceu-se como uma instituição laica, republicana e pública, sendo que as lutas sociais do século XX afirmaram-na também em sua faceta democrática. Contudo, as contradições que se estabelecem nos contex- 
tos em se insere tornam latente concepções divergentes em seu ordenamento e em sua função social. Chauí (2003), citando Freitag (1996), afirma haver a universidade como instituição e a universidade como organização.

No primeiro formato, constituído através de um Estado democrático e republicano, prima-se pela autonomia e pela universalidade, tendo a sociedade como referência de um processo formativo pautado na liberdade intelectual. No segundo modelo, que tem como base a Reforma do Estado e a definição da educação como um serviço não-exclusivo da esfera pública, a universidade é vista como uma organização que se baliza na eficácia, na eficiência, no controle da/pela gestão, na flexibilidade, na produtividade e na adaptação às demandas do mercado, entre outras concepções vinculadas ao setor produtivo e financeiro. $O$ ensino e a pesquisa, nessa perspectiva, apesar de construídos em uma universidade pública, se tornam um conhecimento que vislumbra a apropriação por interesses privados, sem a valoração de preceitos democráticos e republicanos (CHAUÍ, 2003).

Assim, a maneira como é concebida a construção de uma sociedade (e de suas instituições) está em relação com a conjuntura em que se insere. A universidade, mesmo em um esforço de ser pensada sob um viés democrático, entra em choque com concepções neoliberais, que pautam as atividades - especialmente as vinculadas a órgãos públicos - por valores próprios do capital econômico e financeiro. Contradições, dessa forma, são materializadas com movimentos que, em determinados momentos, apontam avanços quanto à participação, enquanto em outros, salientam recuos. A incursão neoconservadora, neste momento histórico, intensifica essa correlação de forças, tornando mais intensas e contraditórias as disputas, que são notórias no ambiente acadêmico.

Essas questões, por mais que possam ser encaradas, muitas vezes, como alienadas da relação entre professor e aluno, relacionam-se com a maneira com que o cotidiano acadêmico se estabelece e com a forma com que as aulas são desenvolvidas. Como Masetto (2005) destaca, toda a aula é regida por um paradigma que, mesmo não sendo explícito, se constitui de valores, conceitos e práticas sustentadas por determinada maneira de entender a realidade. Esse paradigma, de acordo com o autor, precisa ser questionado, revisado e repensado de forma a dar conta da formação requerida pela sociedade e das necessidades de aprendizagem dos sujeitos, e se apoia em três pilares: na organização curricular das disciplinas, na constituição do corpo docente (sua formação e competência pedagógica) e na metodologia utilizada. A forma como a democracia é construída (ou limitada) nas universidades, nesse sentido, também interfere nessas dimensões e na forma como um paradigma 
é instituído e, diante disso, na docência e no processo formativo de jovens e adultos (não somente, mas inclusive) no Ensino Superior.

\section{Os processos de indicação e de nomeação de reitores em universidades federais}

Ao se buscar compreender a maneira como devem ser indicados e nomeados os reitores das universidades federais, verifica-se um ordenamento jurídico complexo, que denotou, ao longo do tempo, a dificuldade em se estabelecer de forma unívoca esse processo. A primeira diretriz que estipulava como deveria ser empreendido o processo de indicação dos dirigentes de instituições de ensino superior no Brasil remonta à época da Ditadura Militar. Em 1968, a Lei no 5.540 fixou as orientações para o funcionamento e a organização do ensino superior, mencionado em sua articulação com a escola média - nomenclatura utilizada na época para se referir à última etapa da, atualmente chamada, Educação Básica (BRASIL, 1968). De acordo com o documento, reitores e vice-reitores seriam nomeados pelo governo a partir de uma lista elaborada pelo Conselho Universitário ou outro colegiado de representatividade similar.

Essa orientação foi alterada pela Lei no 6420/77, que estipulava o Chefe do Poder Executivo como responsável por realizar tal nomeação de acordo com uma lista, dessa vez elaborada por um Colégio Eleitoral Especial formado pelo Conselho Universitário e pelos colegiados máximos de administração e de ensino e pesquisa das instituições (BRASIL, 1977). Essas orientações, bem como as demais constantes nos texto normativos, foram revogadas na década de 1990, mas as alterações no processo decisório, por mais que indicativas de avanços democráticos, não resultaram em rupturas com vínculos de submissão ao governo federal, mesmo com a indicação, no artigo 207 da Constituição Federal de 1988, da garantia de autonomia universitária (BRASIL, 1988).

A Lei de Diretrizes e Bases da Educação Nacional (BRASIL, 1996) previa, no artigo 56, que as instituições de ensino superior públicas seriam pautadas pela gestão democrática, com colegiados que se constituíam em instâncias deliberativas formadas por representantes regionais, locais e institucionais. Afirmava, também, que $70 \%$ dos assentos nesses órgãos (entre os quais estão aqueles responsáveis pela escolha dos dirigentes) seriam ocupados por docentes. A definição dessa porcentagem reforçava o estipulado pela Lei no 9192/95, que citava, ainda, a nomeação de reitores e vice-reitores como responsabilidade do Presidente da República mediante o envio de uma lista tríplice organizada pelo colegiado máximo das instituições ou outro designado 
para a tarefa (BRASIL, 1995). Previa-se que, mesmo com a consulta - facultativa - à comunidade para a elaboração dessa lista, o peso de 70\% por cento para os docentes seria mantido, mencionando-se, ainda, que os servidores indicados por meio de votação uninominal aos cargos deveriam ter o título de doutor ou fazer parte dos dois níveis mais elevados da carreira.

No entanto, distintas universidades adaptavam esse percentual, realizando consultas, ainda que consideradas informais, às suas comunidades acadêmicas e valorando seus três segmentos com a mesma representatividade. Como nos últimos governos havia sido criada uma tradição de que o nome mais votado da lista tríplice fosse o nomeado pelo governo federal, mesmo não havendo regulamentação jurídica para tal, o processo decisório se materializava como mais democrático. A Universidade Federal de Santa Catarina salientava-se como um desses casos, como retratado na Resolução no 001/2017-18 da Comissão Eleitoral de entidades representativas da Universidade Federal de Santa Catarina (SANTA CATARINA, 2017). Discentes, docentes e servidores técnico-administrativos, segundo o documento, teriam um terço da representatividade dos votos para cada uma de suas categorias, em uma construção mais igualitária.

Projetos de lei buscavam regulamentar formatos mais equânimes e que garantissem a vontade da comunidade nos processos eletivos. Tramitou no Senado o Projeto de Lei no 379/13, que previa a distribuição paritária dos votos entre os três grupos formados pela comunidade acadêmica (BRASIL, 2013). Nesse formato, a nomeação do reitor e do vice-reitor seriam de responsabilidade do governo federal, contudo, não havia menção à lista tríplice, sendo que professores, servidores e alunos possuiriam, igualmente, sua representação mantida com um terço dos votos. O Projeto construía, em sua justificação, o argumento de que, com a gestão democrática prevista no ensino público, a votação direta seria o mecanismo mais adequado para garantir legitimidade aos processos de tomada de decisão, incluindo, de fato, as comunidades.

Outro Projeto de Lei mais recente, o PL 4998/19, também buscava realizar alterações nesse processo (BRASIL, 2019b). Nele, a porcentagem de $70 \%$ da representação docente no colegiado responsabilizado pelo processo decisional é mantida. A consulta à comunidade acadêmica igualmente é mencionada, preservando a observância da mesma porcentagem para o grupo docente. Contudo, o projeto buscava regulamentar que os nomes do reitor e do vice-reitor escolhidos como os preferidos pela comunidade seriam os nomeados pelo Presidente da República. Nesse aparato, não havia a citação de lista tríplice nem a possibilidade de que atores do governo federal pudessem 
escolher os dirigentes das universidades.

As discussões a respeito dessas questões se intensificaram recentemente devido à equipe de governo que tomou posse em 2019 no âmbito federal ter agido de modo distinto, com relação a governantes anteriores, para a nomeação dos dirigentes das universidades. Até o final de novembro desse ano, doze instituições públicas de ensino superior procederam a escolha de seus reitores, todavia apenas a metade delas teve o nome indicado pela comunidade avalizado, o que contrariou uma tradição já instituída. Mirlene Damázio foi nomeada reitora da Universidade Federal da Grande Dourados (UFGD), em 11 de junho, mesmo sem fazer parte da lista tríplice enviada pela instituição ao governo. Na Universidade Federal do Triângulo Mineiro (UFTM), foi nomeado como reitor, no dia 17 de junho, Luiz Fernando Resende dos Santos Anjo, segundo colocado na lista tríplice. Em $1^{\circ}$ de agosto, ocorreu a nomeação de Fábio Josué Souza dos Santos, último colocado na lista tríplice da Universidade Federal do Recôncavo da Bahia (UFRB). Janir Alves Soares, igualmente último posicionado na lista tríplice, foi nomeado em 10 de agosto o novo reitor da Universidade Federal dos Vales do Jequitinhonha e Mucuri (UFVJM). Na Universidade Federal do Ceará (UFC), José Cândido Lustosa Bittencourt de Albuquerque foi nomeado reitor, em 19 de agosto, embora sendo o segundo colocado. Na Universidade Federal da Fronteira Sul (UFFS), o terceiro colocado da lista tríplice - Marcelo Recktenval - foi nomeado, no dia 30 de agosto, como reitor. Ainda, houve intervenção do governo na nomeação do diretor do CEFET-RJ - Centro Federal de Educação Tecnológica do Rio de Janeiro -, ocorrida em 15 de agosto. Maurício Aires Vieira, que era assessor de Abraham Weintraub, um dos ministros da educação do governo, foi o nome escolhido, mesmo sem ter vínculo com a instituição².

Em entrevistas ou notas divulgadas pela equipe de governo quanto às opções não condizerem com as expectativas da comunidade, o argumento usado foi de que não haveria hierarquia na lista tríplice e que a decisão seria do presidente ${ }^{3}$. Isso contrariou uma conduta institucionalizada em que o nome preferido pela universidade seria oficializado como seu gestor. Entidades representativas da classe docente e grupos vinculados à educação divulgaram notas e manifestos em reprovação às decisões, como o Conselho de Unidade do Centro de Ciências da Educação da UFSC e o Colegiado do Programa de

2 Tais informações estão sistematizadas em: https://apubh.org.br/noticias/em-9-meses-6-intervencoes-em-universidades/. Acesso em: 12 jan. 2020.

3 Essa informação pode ser conferida na íntegra em: https:/g1.globo.com/educacao/noticia/2019/08/31/ governo-interveio-em-6-de-12-nomeacoes-de-reitores-de-universidades-federais-ate-agosto.ghtml. Acesso em 11 jan. 2020.

Rev. Fac. Educ. (Univ. do Estado de Mato Grosso), Vol. 35, Ano 20, № 1, p. 51-69, jan/jun, 2021. 
Pós-Graduação em Geografia da UFFS ${ }^{4}$. O caso da UFFS se destaca, ainda, pela comunidade demonstrar de forma mais explícita a insatisfação com a situação imposta, sendo que, durante cerca de 20 dias, acadêmicos ocuparam a reitoria da universidade, em Chapecó, Santa Catarina, como protesto à escolha arbitrária do governo, impossibilitando as atividades rotineiras ${ }^{5}$.

Corroborando com o cenário exposto, mesmo contrariando uma parcela substantiva das comunidades acadêmicas, no dia 24 de dezembro de 2019 foi divulgada a Medida Provisória 914, que ratificou tal percepção do governo federal ao pautar a gestão das universidades públicas (BRASIL, 2019a). Nela, institucionalizou a eleição de reitores (o que poderia ser encarado como um avanço), mas confirmou o percentual de participação docente em $70 \%$ dos votos, dividindo a porcentagem restante igualmente entre alunos e técnicos-administrativos. Ainda, indicou que os nomes dos três representantes da comunidade mais votados devem ser enviados à Presidência, que poderá nomear qualquer um deles para assumir a reitoria das instituições de ensino superior. $\mathrm{O}$ gestor nomeado, conforme o artigo 6으, escolherá seu vice-reitor e os sujeitos que ocuparão cargos em comissão e funções de confiança, entre eles os diretores gerais de campi e os diretores e vice-diretores das unidades. A medida manteve a exigência de que os candidatos ao cargo de gestão pertençam aos níveis mais elevados da carreira docente, entre os quais o reitor nomeado escolherá também o vice-reitor. Além disso, o documento regulamentou o afastamento durante a candidatura, os casos em que poderá ser designado um reitor pro tempore e a votação com formato eletrônico para efetivar o processo eletivo.

Nessa construção, convém considerar que o Ensino Superior mantido pelo Estado, de forma mais intensa a partir do pleito eleitoral de 2018, tem sido alvo de ataques, geralmente pautados em notícias falsas, quanto a diferentes aspectos. Como exemplo, tem-se o caso em que uma fotografia de jovens nus em uma sala, amplamente divulgada em redes sociais e em aplicativos de mensagens, foi vinculada a atos que aconteceriam em universidades públicas $^{6}$. Ainda que com amostras e campanhas ${ }^{7}$ que esclareceram sua inverdade

4 Essas notas de repúdio podem ser acessadas em: https://www.uffs.edu.br/campi/chapeco/cursos/mestradoch/mestrado-em-geografia/informes/mocao-de-repudio-a-nomeacao-de-reitor-da-uffs e https://www. nsctotal.com.br/noticias/estudantes-desocupam-reitoria-da-uffs-no-oeste-de-sc. Acesso em 12 jan. 2020. 5 Uma notícia que divulgou a iniciativa em questão está disponível em: https://www.nsctotal.com.br/ noticias/estudantes-desocupam-reitoria-da-uffs-no-oeste-de-sc. Acesso em 12 jan. 2020.

$6 \mathrm{Um}$ dos registros desse movimento pode ser acessado em: https://g1.globo.com/fato-ou-fake/noticia/2019/05/20/e-fake-que-foto-mostra-estudantes-nus-em-universidade.ghtml. Acesso em 12 jan. 2020. 7 Ações coletivas buscaram desconstruir essa percepção, como disponível em: https://brasil.elpais.com/ brasil/2019/05/07/politica/1557244462_796491.html. Acesso em 12 jan. 2020. 
e situaram o real contexto da imagem, houve comoção de certos grupos da sociedade sobre esse fato, questionando a "balbúrdia" (termo usado por esses sujeitos) que aconteceria nessas instituições. Outros discursos relacionados com o que seria uma doutrinação (para a formação de militantes de esquerda) realizada pelos docentes no âmbito acadêmico, repetidos por personagens políticos ${ }^{8}$ vinculados a partidos à direita do espectro ideológico partidário, também alimentaram situações de fake news similares.

Fatos isolados voltados à produção e ao consumo de drogas ilícitas nesse âmbito, inclusive, foram amplamente divulgadas e replicadas, distorcendo os fatos e restringindo as atividades discentes no âmbito acadêmico público a tais eventos, que resultaram, inclusive, em um projeto de lei que visa detectar usuários ${ }^{9}$ nas universidades. Mediante esses fatos, deu-se densidade à retórica de que essas instituições estariam desvirtuadas de valores familiares e cristãos, reforçando julgamentos e condenações à atuação das instituições federais de ensino superior. Articuladas a isso, reportagens veiculadas na mídia quanto ao que seriam os altos gastos para a manutenção das universidades ratificaram intenções, não concretizadas, mas amplamente aceitas em dados grupos, quanto a cobranças de mensalidades nessa esfera ${ }^{10}$. Ainda, nesse mesmo ano, houve um contingenciamento ${ }^{11}$ de $30 \%$ no orçamento das instituições federais de ensino superior, revogado meses depois, mas que causou preocupações quanto à continuidade das atividades educativas.

Assim, o contexto em que se situam as decisões que são alvo dessa análise traz indícios que auxiliam na sua compreensão. Como será discutido em seguida, os processos de indicação e de nomeação de reitores para atuarem em universidades federais denotam as correlações de forças quanto às expectativas de representatividade da comunidade em seus cargos de liderança e as posições dos governantes e de parte da sociedade quanto ao tema. Nesse sentido, tais contradições serão discutidas, mediante o referencial explicitado anteriormente, como forma de buscar construir uma reflexão a respeito das implicações das medidas tomadas pelo governo na construção da democracia nas universidades públicas.

8 Disponível em: https://istoe.com.br/as-universidades-estao-tomadas-pela-esquerda/. Acesso em 12 jan. 2020.

9 A questão pode ser melhor compreendida a partir do link: https://www.otempo.com.br/politica/deputado-quer-exame-para-detectar-consumo-de-drogas-em-universidades-1.2082388. Acesso em 14 jan. 2020. 10 Disponível em: https://www.gazetadopovo.com.br/educacao/programa-de-bolsonaro-preve-cobranca-de-mensalidades-em-universidades-publicas-7opv4rk31rasxrshapaykn44y/. Acesso em 14 jan. 2020.

11 Os efeitos desses cortes podem ser entendidos a partir de: https://g1.globo.com/educacao/noticia/2019/08/17/cortes-na-educacao-vao-afetar-aulas-a-partir-de-agosto-dizem-universidades-federais. ghtml. Acesso em 14 jan. 2020.

Rev. Fac. Educ. (Univ. do Estado de Mato Grosso), Vol. 35, Ano 20, № 1, p. 51-69, jan/jun, 2021. 


\section{Universidade e democracia}

Como abordado na seção primeira deste estudo, há diferentes construções que buscam explicitar os significados do termo democracia. Wood (2003) aponta para a vinculação entre o político e o econômico, desfeita pelo capitalismo, para que se possa concretizar uma sociedade efetivamente pautada pela participação dos sujeitos. Para isso, a privatização da esfera política pelo capital precisa ser desfeita, com sua reapropriação pelos trabalhadores (que deixam de ter sua atuação em sociedade reduzida a uma abstração), ponto que a liga a Mészáros (2002), que reforça a necessidade de que o controle social volte para as mãos dos cidadãos. Para ele, a democracia precisa ser entendida como uma construção para a qual não há manuais ou receitas, mas que precisa ser empreendida pela prática social em um processo permanente de autocrítica e crítica. Vieira (1998) corrobora com tal construção ao enfatizar a dimensão processual da democracia, acrescentando a necessidade de que as decisões sejam pautadas pela coletividade, já que essa construção é garantida pela crescente participação dos sujeitos.

A par dessas considerações, convém refletir sobre o processo de indicação e de nomeação dos reitores das universidades federais e seu caráter democrático. Em um formato particular, pode-se resumir essa deliberação, atualmente, como a escolha empreendida pela comunidade acadêmica (mantendo-se a representação dos docentes em 70\%) de três nomes dentre os quais o Presidente da República opta por um para nomear como o reitor da instituição. Havia, como descrito, uma regulamentação vaga anteriormente, permitindo variações em algumas instituições, que buscavam flexibilizar esse formato de maneira a torná-lo mais equânime, e também projetos de lei que reforçavam essa dimensão e intencionavam definir para o cargo o docente com maior aprovação da academia.

Essa construção formal, no entanto, traz questionamentos quanto a seu caráter democrático, considerando-se que não consta na legislação a paridade entre os entes da comunidade (prevalecendo a figura do professor) e o fato de que, anteriormente, a escolha podia se dar através de colegiados. Convém mencionar a importância dessa instância de tomada de decisão para a participação, no entanto, restringir a responsabilidade de escolha de reitores a eles excluía uma totalidade que poderia não se sentir ouvida de forma direta, nem acolhida em todas as suas posições. Assim, o voto individual (que a Medida Provisória 914 regulamentou e que pode ser encarado como um avanço) e paritário (ainda não considerado na legislação) pode ser traduzido 
como uma maneira de tornar o processo de tomada de decisão mais participativo e igualitário, sem se desconsiderar a atuação dos colegiados em outras medidas. Afinal, como reforça Vieira (1998), quanto mais se discutir e quantos mais estiverem envolvidos na resolução acerca de uma decisão, mais democrático se salienta esse movimento. Além disso, só por meio da crítica e da autocrítica (em uma percepção de Mészáros, 2002, que pode ser relacionada às instâncias deliberativas individuais e coletivas) é possível avançar na construção da democracia.

O formato de escolha dos gestores das universidades públicas caracterizou-se, por muito tempo, como um ordenamento jurídico vago em determinados pontos, que deixava brechas para interpretações distintas. Entre elas, cabia a utilizada como argumento pelo governo federal para não nomear como gestores os nomes mais indicados em seis universidades durante 2019, já que esse princípio não estava expresso na legislação. No entanto, por meio da proposição de uma Medida Provisória, o Poder Executivo formalizou, ao final de 2019, a si mesmo como o responsável por escolher os reitores, mesmo que se utilizando de uma manobra que poderia ser considerada democrática, se observada isoladamente, com a proposição de eleições nas universidades (BRASIL, 2019a).

Essas eleições, no entanto, passam apenas a indicar três possibilidades a partir das quais a Presidência da República pode deliberar, instituindo seu poder de decisão arbitrário na escolha desses gestores. Esse documento ainda empodera os reitores nomeados a escolherem os vice-reitores e os demais atores a desempenharem cargos em comissão e funções de confiança, fazendo com que todos os cargos com representatividade e com amplo poder de decisão possam estar vinculados às percepções da equipe de governo. A democracia, assim, se torna frágil quando pautada no universo acadêmico, já que a desconsideração da opinião de uma comunidade em um processo eletivo acaba por impedir, mesmo que de forma ensaística e parcializada, que o controle social, mencionado por Mészáros (2002), esteja nas mãos dos sujeitos implicados no movimento em análise.

Convém, questionar, contudo, o que motiva, ideologicamente, uma equipe de governo eleita em um processo democrático a não ter aceitado o resultado de um embate similar. Nesse sentido, recorre-se ao conceito de Estado, abordado por Harvey (2005), que define essa esfera (na sociedade capitalista) não como um ente que age apenas pautado pelo bem comum, em um protocolo abstrato de ações guiadas pelas necessidades de seu povo. Para o autor, o Estado se estabelece como uma esfera que atua, por meio de 
estratégias distintas que tornam invisível tal conotação, em favor das classes dominantes, daqueles que detêm o capital. A equipe de governo que o representa, nessa compreensão, reproduz os ideais do tempo histórico estabelecido que, na atual conjuntura macroestrutural, remetem às concepções neoliberais e neoconservadoras que orientam as práticas e as relações, não somente econômicas, mas também sociais.

Como Peroni (2005) retrata, o neoliberalismo (período que intensifica as prescrições do capitalismo) compreende as instituições estatais como ineficientes e ineficazes ao se constituírem por meio das deliberações da população, que exige políticas sociais, providas - nessa percepção - com arrecadações que sobrecarregariam determinados estratos e com a intervenção na economia. Nesse sentido, prega o livre mercado, a atuação do Estado seguindo os padrões do capital e o esvaziamento de participação da população nas instituições públicas. As universidades, recorrentemente mencionadas, como descrito anteriormente, como instituições com altos custos ao Estado, precisariam, assim, ser expostas a estratégias mais próximas de tais orientações. Ilustra, no contexto analisado, tal questão, o fato de estar havendo um movimento nas universidades federais para que estas adiram ao Programa Universidades e Institutos Federais Empreendedores e Inovadores - Future-se ${ }^{12}$, iniciativa do governo que estimula parceiras público-privadas e que enfrenta resistências em muitas instituições. Assim, sem a permeabilidade democrática e com sujeitos vinculados aos interesses da equipe de governo, essa e outras ações, tenderiam a se concretizar com maior facilidade.

Articulado a isso é importante destacar a faceta neoconservadora desse movimento. Retornando a Harvey (2005), com o objetivo de restaurar valores e princípios considerados como cristãos e nacionalistas, esse movimento busca trazer uma aura de estabilidade ao caos instaurado diante das contradições do capitalismo. Essas concepções tiveram como um de seus principais alvos, em um período recente em nosso país, as instituições públicas de ensino superior. Com retóricas relacionando-as à permissividade moral e ao ataque a valores familiares e cristãos, ilustrados com fake news vinculadas à nudez, ao uso e produção indiscriminados de drogas ilícitas e ao que seria uma doutrinação de esquerda pelos docentes, arquitetou-se um cenário de desvalorização do ensino superior público. A ideia de se destituir de representatividade a universidade pública, assim, se constrói como uma ideia aprazível, que poderia inserir novos sujeitos (identificados com um ideário contrário ao

12 Essa questão pode ser conferida na íntegra em: https://www.politize.com.br/future-se-entenda-a-nova-proposta-do-mec/. Acesso em 12 jan. 2020. 
prevalecente) e que poderia modificar esse cenário.

Além disso, o discurso de que esses ambientes formativos teriam altos custos à população, sendo inclusive destituídos de parte significativa de seus orçamentos e estimulados a manterem parte de suas atividades com recursos oriundos do setor privado - em referência ao Future-se -, corrobora com a instauração de um modelo empresarial na universidade. Nele, a democracia não seria necessária, em um movimento em que a não aceitação dos resultados das escolhas de reitores em universidades colabora com a instauração de uma universidade com um padrão organizacional e corporativo, como Chauí (2003) problematiza. Ao invés de haver um fortalecimento das instituições de ensino superior como instâncias de ensino, pesquisa e extensão autônomos, plurais e democráticos, busca-se estimular o desenvolvimento de respostas para necessidades do mercado, de produtividade e de controle, inclusive da gestão, como no caso em análise. Essa construção, nesse sentido, seria facilitada com sujeitos que se identificassem com essa ideologia, indicados mediante uma escolha destituída de vontade pública e democrática, feita pelo Estado mediante seus governantes.

As instituições públicas de ensino superior e seus processos de definição de reitores, assim, se tornam formas particulares de, como problematizado por Lukács (1978), vincular os espaços formativos singulares ao contexto estrutural do capitalismo e de suas demandas formativas, com a gestão sendo a forma de garantir essa relação. E o esvaziamento da democracia desses movimentos garante sua efetividade e a consolidação de uma universidade como organização (CHAUÍ, 2003) que, mesmo sendo (ainda que parcialmente) mantida com recursos públicos oriundos das contribuições de toda a população, pauta suas atividades nas ideologias, concepções e necessidades das classes dominantes. Compreende-se que a construção democrática idealizada por Wood (2003), em que o político e o econômico, enfim, se tornam um, só se torna plenamente possível com a substituição dos interesses financeiros e individuais em voga por uma sociabilidade pautada na participação paritária de todos os cidadãos.

Todavia, a diminuição das distâncias entre esses dois polos pode ser construída, em um processo contínuo de busca por espaços de participação e por legitimidade nas decisões populares, e as instituições públicas e os processos formativos construídos nelas podem ser definidos como esferas decisivas dessa construção. Como Masetto (2005) explica, a maneira com que o currículo e a metodologia são organizados, bem como as concepções que norteiam a formação e a ação pedagógica dos docentes, definem os paradigmas 
que regem a docência e, em relação a isso, a maneira com que o processo de ensino-aprendizagem é empreendido. Em contextos em que a democracia é enfraquecida e concebida com desconfiança, os paradigmas tendem a seguir tal prescrição, comprometendo avanços no âmbito da participação. Contudo, de forma contrária, se os paradigmas resistirem e insistirem em práticas e conceitos reflexivos, interativos e engajados com a construção de ambientes mais democráticos, de forma crítica e autocrítica (como Mészáros, 2002, aponta), a formação universitária pode colaborar com a superação de obstáculos legais e auxiliar no desenvolvimento de uma sociedade mais articulada com ideais de coletividade e de tomadas de decisão conjuntas.

\section{Considerações finais}

Como este estudo buscou refletir, o formato de escolha de reitores utilizado historicamente no Brasil e parcialmente alterado recentemente pelo Poder Executivo não favorece o reconhecimento das decisões democráticas empreendidas pelas comunidades acadêmicas quanto a seus gestores. Por mais que os artefatos jurídicos representem avanços quanto a alguns pontos, como a recente decisão de institucionalizar a eleição pela comunidade de seus reitores, esse artifício se restringe à composição de uma lista tríplice sobre a qual o governo deliberará, sem, necessariamente, seguir a hierarquia dos votos. Mesmo com projetos de lei que propunham opções mais equânimes e que buscavam formalizar na função a opção mais indicada pela comunidade, 0 Poder Executivo optou por uma Medida Provisória, que em si carrega um teor arbitrário, para tornar norma a posição que já havia adotado com a nomeação de seis reitores em universidades federais.

Tal sistemática, assim, se tornou contumaz, sendo recorrente em distintas instituições para além do período enfocado no estudo. Na Universidade Federal de Pelotas, por exemplo, Paulo Ferreira Júnior foi o candidato a reitor mais votado em 2020, mas quem foi nomeada ao cargo pela presidência foi Isabela Fernandes Andrade. Todavia, em comum acordo entre os docentes, foi empreendido um movimento para que Paulo fosse assessor de Isabela e, juntos, pudessem colocar em ação o projeto escolhido pela comunidade ${ }^{13}$. Esse caso se destaca como um exemplo de resistência e de construção, democraticamente, de ações que privilegiem a participação e defendam a autonomia

$13 \mathrm{O}$ caso pode ser conferido em detalhes a partir de: https://g1.globo.com/rs/rio-grande-do-sul/noticia/2021/01/07/contraria-a-decisao-do-governo-federal-ufpel-anuncia-que-sera-comandada-por-dupla-de-reitores.ghtml . Acesso em: 18 jul. 2021.

Rev. Fac. Educ. (Univ. do Estado de Mato Grosso), Vol. 35, Ano 20, № 1, p. 51-69, jan/jun, 2021. 
universitária e o posicionamento de seus atores.

Concluindo, destaca-se que a negligência intencional aos processos eletivos das universidades efetiva um modelo de Estado que age em favor dos interesses das classes dominantes, baseado em concepções neoliberais e neoconservadoras. Não que a escolha de reitores resuma toda a construção democrática das instituições, mas valorizá-la se torna crucial por refletir o modelo de representatividade vigente (ainda que possua muitas críticas e seja passível de aprimoramento) e tornar tácitas as escolhas efetuadas por aqueles que vivenciam, no dia a dia, o cotidiano de cada universidade. Além disso, vivências democráticas consolidam paradigmas de docência amparados em concepções participativas e críticas, que se refletem no processo formativo discente e, da mesma forma, na atuação cidadã desses sujeitos na realidade. A partir disso, qualificam-se e ampliam-se os esforços por uma educação humana, engajada socialmente, que considere a pluralidade e respeite o contraditório, capaz de fazer frente à conjuntura estabelecida e buscar a construção de uma nova sociabilidade.

\section{Referências}

BRASIL. Lei n. 5.540, de 28 de novembro de 1968. Fixa normas de organização e funcionamento do ensino superior e sua articulação com a escola média e dá outras providências. Brasília, DF, nov., 1968. Disponível em: http://www. planalto.gov.br/ccivil_03/leis/L5540.htm. Acesso em: 9 jan. 2020.

BRASIL. Lei n. 6420, de 3 de junho de 1977. Altera a Lei no 5.540, de 28 de novembro de 1968, que fixa normas de organização e funcionamento do ensino superior e sua articulação com a escola média e dá outras providências. Brasília, DF, jun., 1977. Disponível em: https://presrepublica.jusbrasil.com.br/ legislacao/128399/lei-6420-77. Acesso em: 9 jan. 2020

BRASIL. Constituição da República Federativa do Brasil, de 05 de outubro de 1988. Brasília, DF, out., 1988. Disponível em: http://www.planalto.gov.br/ccivil_03/constituicao/constituicaocompilado.htm. Acesso em: 9 jan. 2020.

BRASIL. Lei n. 9.192, de 21 de dezembro de 1995. Altera dispositivos da Lei no 5.540 , de 28 de novembro de 1968, que regulamentam o processo de escolha dos dirigentes universitários. Brasília, DF, dez., 1995. Disponível em: http:// www.planalto.gov.br/ccivil_03/leis/I9192.htm. Acesso em: 10 jan. 2020.

BRASIL. Lei n. 9.394, de 20 de dezembro de 1996. Estabelece as diretrizes e bases da educação nacional. Brasília, DF, dez., 1996. Disponível em: http:// 
www.planalto.gov.br/ccivil_03/leis/I9394.htm. Acesso em: 9 jan. 2020.

BRASIL. Medida provisória n. 914, de 24 de dezembro de 2019. Brasília, DF, dez., 2019a. Dispõe sobre o processo de escolha dos dirigentes das universidades federais, dos institutos federais e do Colégio Pedro II. Disponível em: http://www.in.gov.br/web/dou/-/medida-provisoria-n-914-de-24-de-dezembro-de-2019-235278221. Acesso em: 12 jan. 2020.

BRASIL. Projeto de Lei do Senado n. 379, de 2013. Brasília, DF, dez., 2013. Disponível em: https://www25.senado.leg.br/web/atividade/materias/-/materia/114390. Acesso em: 12 jan. 2020.

BRASIL. Projeto de Lei n. 4998, de 2019. Brasília, DF, set., 2019b. Disponível em: https://www.camara.leg.br/proposicoesWeb/fichadetramitacao?idProposicao $=2219841$. Acesso em: 12 jan. 2020.

CHAUÍ, M. A universidade pública sob nova perspectiva. Rev. Bras. Educ., 2003, n.24, pp.5-15. Disponível em: http://www.scielo.br/pdf/rbedu/n24/ n24a02.pdf. Acesso em: 30 dez. 2019.

HARVEY, D. O neoliberalismo: história e implicações. São Paulo: Edições Loyola, 2005.

LUKÁCS, G. Introdução a uma estética marxista. Rio de Janeiro: Civilização Brasileira, 1978.

MASETTO, M. Docência universitária: repensando a aula. IN: TEODORO, A.; VASCONCELOS, M. L. (orgs). Ensinar e aprender no ensino superior: por uma epistemologia da curiosidade na formação universitária. 2 ed. São Paulo: Cortez/Masckenzie, 2005, p. 79-108.

MÉSZÁROS, I. Para Além do capital. São Paulo, Boitempo, 2002.

PERONI, V. M. V. Implicações da relação público-privada para a democratização da educação. Tese (Professora Titular) - Faculdade de Educação, Universidade Federal do Rio Grande do Sul. Porto Alegre, 2015, 180 p.

SANTA CATARINA. Resolução n. 001, da Comissão Eleitoral de Entidades Representativas da Universidade Federal de Santa Catarina (COMELEUFSC) 2017-18, de 21 de novembro de 2017. Florianópolis, SC, nov., 2017. Disponível em: http://comeleufsc.paginas.ufsc.br/files/2017/12/resolu\%C3\%A7\%C3\%A3o-1-comeleufsc.pdf. Acesso em: 11 jan. 2020.

VIEIRA, E. O estado e a sociedade civil perante o ECA e a LOAS. Revista Serviço Social e Sociedade, n. 56, ano XIX, março de 1998. 
WOOD, E. Democracia contra o capitalismo. São Paulo: Boitempo editorial, 2003.

Data de recebimento: 16.10 .2020

Data de aceite: 22.06.2021 